American Journal of Infectious Diseases 1 (2): 84-86, 2005

ISSN 1553-6203

(c) 2005 Science Publications

\title{
Prevalence, Types and Risk Factors for Malnutrition in Displaced Sudanese Children
}

\author{
${ }^{1}$ Nuha Mamoun, ${ }^{1}$ Susan Homedia, ${ }^{2}$ Mustafa Mabyou and ${ }^{1}$ Hussan M. Ahmed Muntasir \\ ${ }^{3}$ T. Salah and ${ }^{1,4}$ Ishag Adam \\ ${ }^{1}$ The Academy of Medical Sciences and Technology, Khartoum, Sudan \\ ${ }^{2}$ College of Medicine, International University of Africa \\ ${ }^{3}$ Ribat University, Sudan \\ ${ }^{4}$ Faculty of Medicine, University of Khartoum, Sudan
}

\begin{abstract}
The nutritional status of 327 under-five children living in Mayoo displacement camp, Khartoum, Sudan, was assessed during May- August 2004. Risk factors for protein-energy malnutrition (PEM) were also studied. According to WHO criteria, a total of $186(56.1 \%)$ children had malnutrition, of these 101(30.1\%), $43(13.1 \%)$ and $42(12.8 \%)$ were mildly, moderately and severely malnourished respectively. According to Welcome classification, the commonest type of malnutrition was found to be underweight $(38.2 \%)$, marasmus, kwashiorkor were detected in $(6.4 \%)$ and $(0.9 \%)$ respectively, there was no case of marasmic kwashiorkor in the studied population. Prevalence of vitamin "A" was $9.2 \%$ of which $0.9 \%$ had night blindness. Age, sex, lack of immunization, lack of breast -feeding, history of fever and history of diarrhoea were tested and were not found be risk factors for malnutrition in this group of children.
\end{abstract}

Key words: Sudan, prevalence, types, risk factors, malnutrition, children

\section{INTRODUCTION}

WHO estimates that 175 million children in the developing world are malnourished as indicated by low weight for age and 230 million are stunted as indicated by height for age ${ }^{[1]}$. It is recognized that the vast majority of deaths among children in the developing world is associated with malnutrition ${ }^{[1,2]}$.

Childhood is a time of active growth in terms of physical size, mental, emotional, sexual maturation and psychological development. Normal growth is dependant on adequate nutrition and encompasses major transformations from birth to adulthood, progressing in an ordered stepwise fashion. Human body can use carbohydrates, fat, proteins as a source of energy. When the intake of energy is not optimum, this can lead to malnutrition in the long $\operatorname{run}^{[3]}$. Malnutrition is associated with poor developmental achievement, poor school performance and malnourished children face long -term sequels such as impairment of mental and intellectual capacity ${ }^{[4,5]}$.

Refugees and internally displaced people deserve special care, as they constitute a large proportion world wide. These groups of people are vulnerable to many health crises as they are triggered by many risk factors such as lack of shelter, poor personal hygiene and poor environmental sanitation, outbreaks of diseases, war, drought, famine and shortage of food.

Since its resumption in 1983, the civil war in Sudan has resulted in estimates of over 2 millions dead,
4 millions internally displaced and over 400000 refugees ${ }^{[6] .}$

The objective of this work was to investigate the prevalence and determinants of malnutrition to provide useful guidelines for the planning of intervention to deal with this problem.

\section{MATERIALS AND METHODS}

Prospective cross sectional surveys were conducted during May- August 2004 in Mayoo displacement camp, in Khartoum, Sudan. 10\% of the house holds were randomly selected and the nutrition status of their children (1-5 yrs) was assessed.

After a verbal consent from the parents, a pretested questionnaire containing a related sociodemographic factors and inquiries were made regarding the possible risk factors for malnutrition (parents' educational levels, presence and absences of parents, history of persistent diarrhoea and fever in the last month, bottle feeding, breast feeding and immunization status) were filled. A thorough examination was done (looking for pallor, Jaundice and signs of vitamin A deficiency in the eyes, skin changes, hair changes, angular stomatitis, hepatomegally and oedema. Then the height, weight, middle upper arm circumference (MUAC) and skin fold thickness were measured, but the later was cancelled because children were unfamiliar with it and were too frightened.

According to recent recommendations ${ }^{[7]}$, each visit the weighing scale was adjusted with a standard one

Corresponding Author: Ishag Adam, Faculty of Medicine, University of Khartoum, Sudan, Tel: +249 912168988

Tel: +249 183 224762, Fax: +249183224799 
and the child was weighted in kilograms (corrected to the nearest decimal) without slippers and most of the clothes.

A centimetre tape was used to measure the mid upper arm circumference, which was taken as the point midway between the acromian process of the scapula and the olecranon fossa at the elbow joint and the reading was corrected to the nearest decimal point.

The Modified welcome classification ${ }^{[8]}$ was used to determine the type of malnutrition (underweight, Marasmus, Kwashiorkor, Marasmic kwashiorkor). A modified waterloo ${ }^{[9,10]}$ was adopted to investigate the chronicity of the problem. The malnutrition was classified according to the WHO classification, as it is recommended by most manuals issued by United Nations agencies, it is robust, independent of age and its interpretation is based on wide experience in many parts of the world ${ }^{[11]}$.

Statistical analysis: The data was entered in microcomputer and SPSS for windows was used for analysis. The means of the age, weight, height and MUAC were compared between the malnourished and none malnourished groups using student $t$-test. Logistic regression model was built, using malnourished as depending variable and the expected risk factors (Age, sex, lack of immunization and lack of breast -feeding, history of fever and history of diarrhoea) as influencing it. Significance was taken as a $P<0.005$.

\section{RESULTS}

A total 327 children from 200 families were enrolled to the study. According to WHO criteria the prevalence of malnutrition was 56.1, 30.9, 13.1 and $12.8 \%$ were mildly, moderately and severely malnourished, respectively.

Underweight, marasmus and kwashiorkor constituted $38.2,6.4$ and $0.9 \%$ of the type malnutrition respectively. There was no case of marasmuskwashiorkor in the study populations.

Prevalence of vitamin A deficiency was found to be $8.3 \%$ as indicated by conjunctival and corneal xerosis, while $0.9 \%$ had night blindness.

The was no significant association of expected risk factors (last month diarrhoea, last month fever, artificial bottle feeding, absence of parents, parents' educational levels and vaccination) with malnutrition using univariate and multivariate analysis (Table 1\&2).

\section{DISCUSSION}

Childhood malnutrition is a major issue in developing countries that requires intervention. The study showed that the prevalence of malnutrition among children in the camp was high $(56.1 \%)$.
Table 1: Comparison of mean (SD) of age, weight, height and MUAC between the malnourished and none malnourished children

\begin{tabular}{lll}
\hline The mean $(\mathrm{SD})$ of & Malnourished & Non malnourished \\
& $\mathrm{N}(186)$ & $\mathrm{N}(141)$ \\
\hline Age, years & $3.03(1.2)$ & $3.06(1.2)$ \\
Weight, Kg & $10.4(2.7)$ & $12.6(3.07)$ \\
Height, Cm & $90.8(11.2)$ & $91.04(15.3)$ \\
MUAC, Cm & $14.3(1.7)$ & $15.28(1.5)$ \\
\hline
\end{tabular}

In the neighbour Ethiopia there were $48 \%$ of malnurioned children ${ }^{[12]}$. However, it is in the range stated by Harrison for the Sudanese children ${ }^{[13]}$.

The finding that the rate of malnutrition in children from households that can be defined as "poor" in relative terms in the district is more than four times the rate for the "better off" provides a strong indication that malnutrition is linked to overall poverty levels. The main reason for this high prevalence of malnutrition is due to lack of proper food. Although children receive an average of 2-3 meals per day but the quality of the food is poor.

The study showed none of the tested factors was associated with malnutrition and there was no age and sex predilection. Yet, in the neighbour Kenya, children in their second year of life were more likely to be underweight, stunted and lack vaccine and respiratory tract infection were the risk factors for malnutrition ${ }^{[14]}$. In Pakistan different results were obtained in regard to female susceptibility to the malnutrition ${ }^{[15,16] \text {. }}$

In this study, there was no significant association between malnutrition and diarrhoea, infection, lack of immunization, one parenthood absence or their education. Previously diarrhoea and infection (cough) and low level of immunization were the risk factors for stunting growth in Sudanese children ${ }^{[17,18]}$.

Surprisingly, the study showed that the lack of beast-feeding was not associated with malnutrition. Previously this problem was addressed in Sudan in more detailed and breast- feeding was encouraged to counteract malnutrition [17]. This issue has been controversial, some authors suggest that the relationships between prolong breast- feeding and malnutrition may indicate a maternal decision to continue breast feeding to a nutritionally disadvantaged child $^{[2,12] \text {. }}$

The study also highlighted the high prevalence of vitamin " $\mathrm{A}$ " deficiency $9.2 \%$ among the children as indicated by conjunctival and corneal xerosis and bitot's spots. This is high in comparison to the previous results from different areas of Sudan and it is well above the WHO threshold of $0.5 \%$ denoting significant vitamin A deficiency ${ }^{[2,19] \text {. }}$

The percentage emphasizes the importance of balanced meals and it may be reflected on the high under five mortality rates. 
Table 2: Factors associated with malnutrition using univariate or multivariate analysis

\begin{tabular}{|c|c|c|c|c|c|c|}
\hline \multirow[b]{2}{*}{ The variable } & \multicolumn{3}{|c|}{ Univariate } & \multicolumn{3}{|c|}{ Multivariate } \\
\hline & OR & $95 \% \mathrm{CI}$ & $\mathrm{P}$ & OR & $95 \% \mathrm{CI}$ & $\mathrm{P}$ \\
\hline Bottle feeding & 1.2 & $0.75-2.08$ & 0.18 & 1.2 & $0.72-2.03$ & 0.4 \\
\hline No- breast feeding & 0.7 & $0.18-3.3$ & 1.0 & 0.7 & $0.1-3.05$ & 0.6 \\
\hline Absence of the mother & 1.08 & $0.43-2.6$ & 0.3 & 2.03 & $0.55-7.4$ & 0.2 \\
\hline Absence of father & 0.78 & $0.38-1.5$ & 0.14 & 0.76 & $0.13-4.5$ & 0.77 \\
\hline Absence of both parents & 0.73 & $0.37-1.44$ & 0.41 & 0.49 & $0.18-1.32$ & 0.16 \\
\hline History of fever & 1.3 & $0.87-2.1$ & 0.1 & 1.31 & $0.82-2.1$ & 0.24 \\
\hline History of diarrhoea & 1.2 & $0.8-1.9$ & 0.3 & 1.1 & $0.73-1.8$ & 0.58 \\
\hline
\end{tabular}

\section{REFERENCES}

1. www.WHO.int/inf-fs/en fact sheet no.119.

2. Caulfield, L.E., M. de Onis, M. Blossner and R.E. Black, 2004. Undernutrition as an underlying cause of child deaths associated with diarrhoea, pneumonia, malaria and measles. Am. J. Clin. Nut., 80: 193-198.

3. Fawzi, W.W., M.G. Herrera, P. Nestel, A. el Amin and K.A. Mohamed, 1998. A longitudinal study of prolonged breastfeeding in relation to child under nutrition. Inter. J. Epi., 27: 255-260.

4. Matorell et al., 1992. Long -term consequences of growth retardation during early childhood. In: Hernandez M., Argente J. (eds.), Human growth: basic and clinical Aspect.Amsterdam, Elsevier, pp: 143-149.

5. Hugo, A., B. Patricia, L. Claudia and E.R. Maria, 2001.Growth deficit in Chilean school children. J. Nutr., 131: 251-254.

6. MSF, 2002. Violence, Health and access to aid in Unity State Western Upper Nile, Sudan. Amsterdam, Medicins Sans Frontieres.

7. HRSA, 2002. Growth chart s training modules. Maternal and Child Health Bureau. http:// depts.washington.edu/growth/.

8. Jellife, D.B., 1966. The assessment of the nutrition status of the community. WHO Monograph No. 53, Geneva: WHO.

9. Waterlow, J.C., 1973. Note on the assessment and classification of protein-energy malnutrition in children. Lancet, 1: 87-89.

10. Waterlow, J.C., 1972. Classification and definition of protein-calorie malnutrition. Brit. Med. J., 3: 566-569.

11. WHO, 1995. Field Guide on Rapid Nutritional Assessment in Emergencies. WHO Regional Office for Eastern Mediterranean.
12. Getaneh, T., A. Assefa and Z. Tadesse, 1998. Protein-energy malnutrition in urban children: prevalence and determinants. Ethio. Med. J., 36: 153-166.

13. Harrison, G.G., 1992. Nutrition and child feeding patterns in the Sudan. Ahfad J., 2: 4-22.

14. Bloss, E., F. Wainaina and R.C. Bailey, 2004. Prevalence and predictors of underweight, stunting and wasting among children aged 5 and under in western Kenya. J. Trop Paed., 50: 260-270.

15. Khuwaja, S., B.J. Selwyn and S.M. Shah, 2005. Prevalence and correlates of stunting among primary school children in rural areas of southern Pakistan. J. Trop. Paed., 51: 72-77.

16. Shah, S.M., B.J. Selwyn, S. Luby, A. Merchant and R. Bano, 2003. Prevalence and correlates of stunting among children in rural Pakistan. Paed Intern., 45: 49-53.

17. Kossmann, J., P. Nestel, M.G. Herrera, A. El-Amin and W.W. Fawzi, 2000. Undernutrition and childhood infections: a prospective study of childhood infections in relation to growth in the Sudan. Acta Paed., 89: 1122-1128.

18. Taha, S.A., 1979 Ecological factors underlying protein-calorie malnutrition in an irrigated area of the Sudan. Ecol. Food and Nutr., 7: 193-201.

19. Nestel, P., M.G. Herrera, A. El Amin, W.W. Fawzi, K.A. Mohammed and L. Weld, 1993. Risk factors associated with xerophthalmia in northern Sudan. J. Nutr., 123: 2115-2121.

20. WHO/UNICEF, 1994. Indicators for assessing vitamin A deficiency and their application in monitoring and evaluating intervention programmes. Geneva: WHO/NUT/94.1. 